This item was submitted to Loughborough's Research Repository by the author.

Items in Figshare are protected by copyright, with all rights reserved, unless otherwise indicated.

\title{
Protection and energy management of zero net electric energy clusters of buildings
}

PLEASE CITE THE PUBLISHED VERSION

http://www.mnnit.ac.in/sces2015/home.php

\section{PUBLISHER}

The IEEE Student Branch, MNNIT Allahabad (@ IEEE)

VERSION

AM (Accepted Manuscript)

\section{PUBLISHER STATEMENT}

This work is made available according to the conditions of the Creative Commons Attribution-NonCommercialNoDerivatives 4.0 International (CC BY-NC-ND 4.0) licence. Full details of this licence are available at: https://creativecommons.org/licenses/by-nc-nd/4.0/

\section{LICENCE}

CC BY-NC-ND 4.0

\section{REPOSITORY RECORD}

Pandey, Gaurav, Sri Niwas Singh, Bharat Singh Rajpurohit, and Francisco M. Gonzalez-Longatt. 2019. "Protection and Energy Management of Zero Net Electric Energy Clusters of Buildings". figshare. https://hdl.handle.net/2134/20505. 


\section{Protection and Energy Management of Zero Net Electric Energy Clusters of Buildings}

\author{
Gaurav Pandey, SN Singh \\ Department of Electrical Engineering \\ Indian Institute of Technology Kanpur \\ Kanpur \\ gpiitk@gmail.com, snsingh@iitk.ac.in
}

\author{
Bharat Singh Rajpurohit \\ School of Electrical \& Computer Sc. \\ Indian Institute of Technology Mandi \\ Himanchal Pradesh \\ bsr@iitmandi.ac.in
}

\author{
Francisco M. Gonzalez-Longatt \\ School of Electronic, Electrical and \\ Systems Engineering \\ Loughborough University, UK \\ F.Gonzalez-Longatt@1boro.ac.uk
}

\begin{abstract}
This paper proposes the protection and energy management schemes for a smart dc micro-grid capable of $100 \%$ autonomous zero net energy in the cluster of buildings to facilitate a low-carbon sustainable electricity supply system. The proposed model comprises of house clusters with an autonomous communication developed for the residential area. Voltage droops and slope compensation peak current mode control techniques are employed for the bidirectional synchronous boost converter stages for energy storage systems (ESSs). The zone relaying device pertaining to dc protection is incorporated under set of rules related to current differential and overt current relaying schemes. The bidirectional converter stage for house clusters plays a pivotal role in stand-alone operation. In case a battery pack is laid off from any house cluster, the dc bus voltage still be stabilized due to the proximity bidirectional converter stages of other house clusters or community battery bank. The houses in the cluster comprise of permanent magnet synchronous generator (PMSG), solar photovoltaic (PV), battery bank and variable load. The proposed model is simulated on MATLAB/ Simulink environment and suffices the real time stochastic nature of wind, solar and load.
\end{abstract}

Index Terms-Distributed generators, Energy storage systems, Peak current mode, State of charge.

\section{INTRODUCTION}

Due to various concerns such as climate change, system security and economy globalization, the dc micro grid is becoming viable option for meeting the ever-increasing electric demand. Governments around the world are putting serious efforts to become decarbonised economies as a part of a national climate change mitigation strategy. The transition to a decarbonised economy involves three main aspects [1]: (i) developing energy efficiency measures, (ii) developing renewable energy capabilities and (iii) to deal with adaptation needs arising due to climate change.

The protection and energy management are the two important issues in the dc micro grids. The dc fault protection schemes can be classified into unit and non-unit protection schemes [2]. The non-unit protection does not consider the bounded zones and operates on the concept of violation of threshold. The protection schemes such as over current, over voltage, and the derivates of current and voltage are involved in non-unit fault detection and can act as a backup protection. The unit protection only protects the bounded zones and works well when grading in over current relays doesn't achieve a satisfactory operation in fault detection due to the complexity in the network. The common practice is to use a differential protection as its operation is less affected by various impedance and fault current value. Fault characterization mechanism is analyzed in two stages [3].

The topologies for dc distribution reported in [4], mainly contains radial type and ring type. The path of power flow is certains in radial type and power flow control is also controllable but the reliability is very low. Secondly, the ring type configuration whereby power flow has two paths and thus resulting in increased fault tolerance, are used in smallscale system like aircraft where continuity of power supply is essential. When a ground fault occurs, the dc link voltage between the positive and negative poles loses a balance and overvoltage at the healthy line will appear due to the dc link capacitors rapid discharge to the ground with very short time constant. This leads to overvoltage at the un-faulted line, which is observed to detect the ground faults. Therefore, TT and TN-S grounding types are the better choices while designing the protection scheme [2].

In this paper, an energy management in a stand-alone dc micro grid is proposed. Voltage droop and slope compensation peak current mode control technique are employed for the bidirectional synchronous boost converter stages for energy storage systems (ESSs). The considered smart dc micro-grid is capable of $100 \%$ autonomous zero net energy in the cluster of buildings to facilitate low-carbon sustainable electricity supply system. The houses in the cluster comprise of permanent magnet synchronous generator (PMSG), solar photovoltaic (PV), battery bank and variable load. For successful operation of a dc micro-grid system, a suitable protection system must be designed. In this work, a protection system is developed. The effectiveness of the proposed energy management and protection system is demonstrated on a test system.

\section{PROPOSED SYSTEM CONFIGURATION}

In the present work, the ring topology as shown in Fig. 1 is considered to connect the house clusters, community load and community battery bank considering the fault tolerance and the continuity of power supply. The variable load of each house cluster comprises of critical and interruptible loads and 
can be laid off according to the deficit of power as per the state of charge (SoC) of the battery pack.

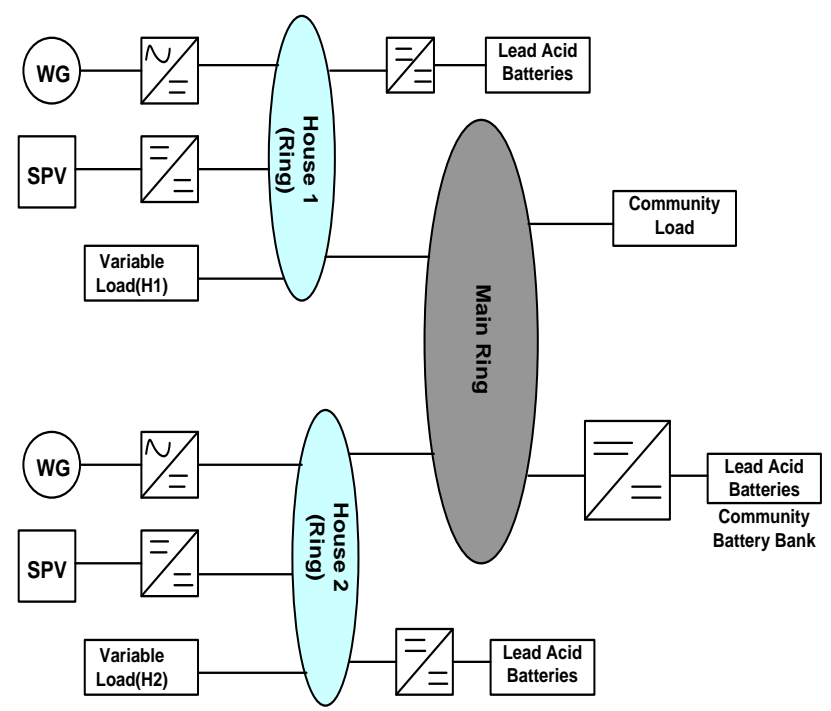

Fig.1. Ring Configuration of house clusters for DC Micro-grid.

The schematic diagram shown in Fig. 2 represents a typical one house cluster detail which is comprised of wind turbine- generator, PV array, battery storage and various loads and the configuration is arranged in unipolar- type dc microgrid. The dc bus voltage considered is $220 \mathrm{~V}$ and is regulated by the bidirectional dc-dc converter control schemes in the isolated mode. The proposed model consists of wind turbine generator of $7.5 \mathrm{~kW}$ operated at maximum power coefficient $\left(C_{p, \text { max }}\right)$ with a fixed $\beta=0^{\circ}$ and $\lambda_{\text {opt }}$. Maximum power extraction is decided at optimal rotational speed [5],[6] [10].

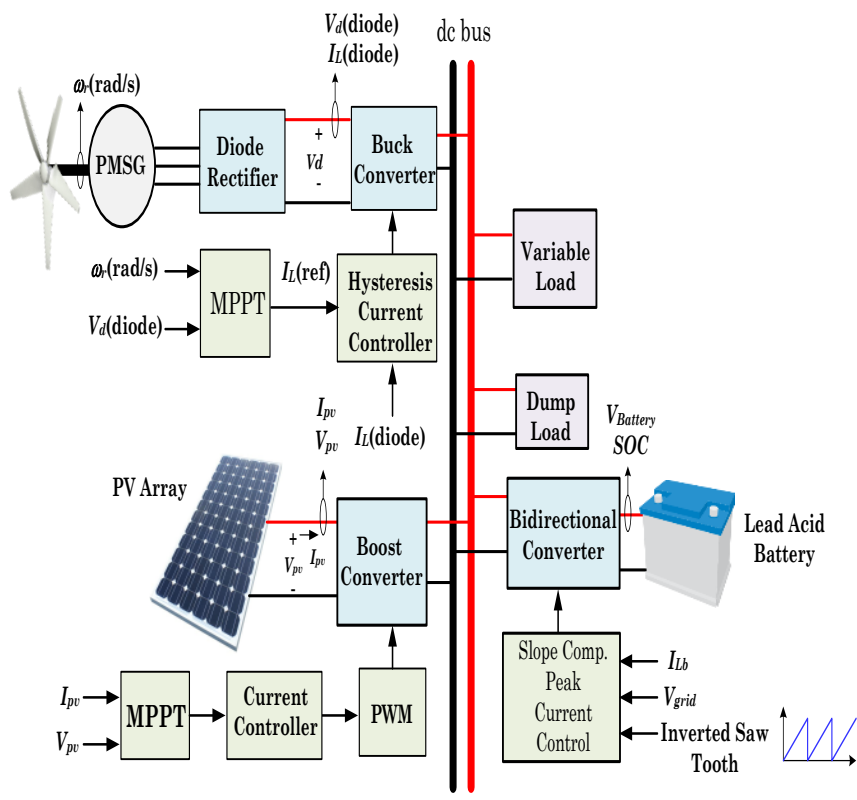

Fig. 2. General representation of the main components in a House cluster configuration.

Diode rectifier with buck converter stage is preferred over back-to-back converter in the islanded operation due to its simplicity. From the power $\left(P_{s}\right)$ and torque equations $\left(T_{e}\right)$, it can be deduced that the rotational speed of PMSG depends on the dc current and it can be regulated by proper control mechanism. Thus, the circuit is cascaded with buck converter whose single switch is controlled with the help of maximum power point tracking (MPPT). The variation in the wind velocity will affect the voltage magnitude and frequency of
PMSG and thus, affects the diode rectifier output. To regulate the dc voltage of buck converter, the duty cycle is adjusted such that machine adjusts its electromagnetic torque to achieve the MPPT.

The solar photovoltaic of $3.5 \mathrm{~kW}$ is cascaded with the boost converter and operating under incremental conductance (IC) MPPT control and analyzed in detail [7].

\section{ENERGY MANAGEMENT CONTROL SCHEME}

Battery converter stage is used for the power balance, cycle by cycle slope compensation for the duty cycle more than $50 \%$ and to stabilize the coupling voltage of the dc bus in stand-alone system. The control strategy realized is shown in Figs. 3 and 4, and they are explained later section. In order to deal with instability issue for duty cycle greater than 0.5 , an additional inverted ramp with slope $m_{a}$ is taken into consideration to check the difference of perturbation occurring in the inductor current and the steady state expected inductor current.

The inductor current transforms from rising slope $m_{1}$, falling slope $m_{2}$ and inverted slope $m_{a}$, and the steady-state condition can be derived.

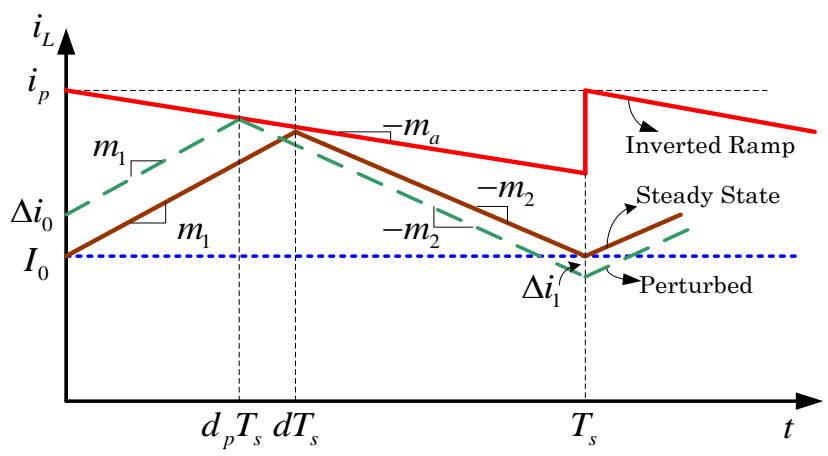

Fig. 3. Steady-state and perturbed waveform of inductor current $\left(i_{L}\right)$.

Without perturbation, the peak current can be directly derived as

$$
\begin{gathered}
i_{p}-m_{a} d T_{s}=I_{0}+m_{1} d T_{s} \\
I_{0}=i_{p}-\left(m_{2}-m_{a}\right)(1-d) \mathrm{T}_{s}
\end{gathered}
$$

Now with the perturbation of $\Delta i_{0}$, the above equations can be written as

$$
\begin{gathered}
i_{p}-m_{s} d_{p} T_{s}=I_{o}+m_{1} d_{p} T_{s}+\Delta i_{0} \\
I_{0}=i_{p}-\left(m_{2}-m_{a}\right)\left(1-d_{p}\right) T_{s}+\Delta i_{1}
\end{gathered}
$$

In both the cases, switching period is same, so it is written as:

$$
d T_{s}+(1-d) T_{s}=d_{p} T_{s}+\left(1-d_{p}\right) T_{s}
$$

where $T_{s}$ is the switching period; $d_{p}$ is the perturbed duty cycle and $I_{0}$ is the average inductor current.

Solving for the subinterval from (1)-(4) and putting the values in (5), the current error shifts after $n$ cycles and the impact of inverted slope compensated ramp can be seen on the steady state by following relation:

$$
\Delta i_{n}=\left(-\frac{m_{2}-m_{a}}{m_{1}+m_{a}}\right)^{n} \Delta i_{0}
$$

For the stable operation of current loop, the following relationship needs to be fulfilled as mentioned in [8]:

$$
\left|\frac{m_{2}-m_{a}}{m_{1}+m_{a}}\right|<1
$$




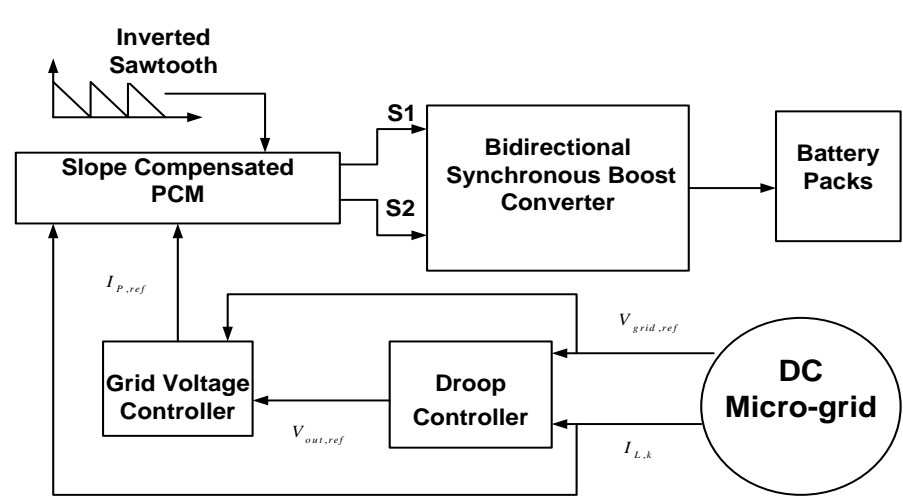

Fig. 4. Bidirectional Control Scheme for Power Sharing and Voltage Regulation

In Fig. 4, the outer droop control loop is incorporated for the current sharing having virtual resistance $R_{d}$ and the characteristic shown in Fig. 5. The value of virtual resistance is calculated as per current sharing concept [4], [12].

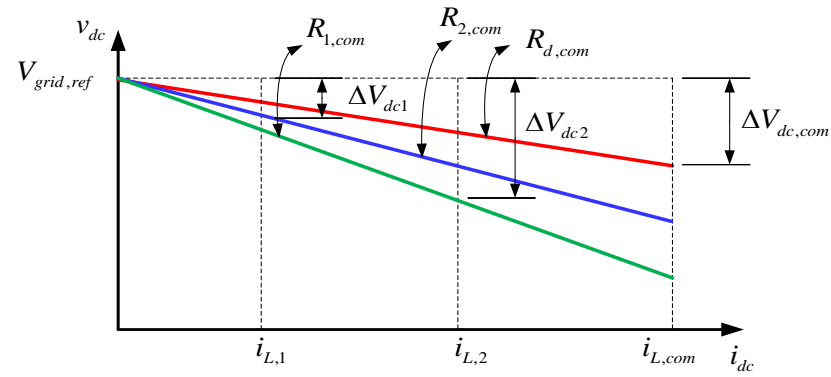

Fig. 5. Voltage-current droop characteristic.

$$
\begin{gathered}
V_{\text {out }, \text { ref }}=V_{\text {grid }, \text { ref }}-i_{L, k}\left(R_{d, k}+R_{c a b, k}\right) \\
\Delta V_{d}=V_{\text {grid, ref }}-V_{\text {out }, \text { ref }}=i_{L, k}\left(R_{d, k}+R_{c a b, k}\right)
\end{gathered}
$$

From (13) and (14), the virtual resistance can be calculated by the symmetry as follows:

$i_{L, 1}: i_{L, 2}: i_{L, \mathrm{com}}=\frac{1}{\left(R_{d, 1}+R_{c a b, 1}\right)}: \frac{1}{\left(R_{d, 2}+R_{c a b, 2}\right)}: \frac{1}{\left(R_{d, c o m}+R_{c a b, c o m}\right)}$

where $i_{L, k}, R_{d, k}$ and $R_{c a b, k}$ are the inductor current, the virtual resistance and the cable resistance for the bidirectional converter for house- 1 , house- 2 and community.

To minimize the voltage deviation, the virtual resistance is designed such that it fulfills:

$$
R_{d, k} \leq \frac{\Delta V_{d c, \text { max }}}{I_{\text {fullload }}}
$$

The next control loop is of the voltage control loop, which will regulate the dc bus voltage operation using charging/ discharging of battery pack having compensator transfer function ' $G_{c v}$ ' which is designed and tuned using bode-plot and pole-zero plot. Further, it will provide reference inductor current taking into account the inverted saw tooth which is compared with feedback inductor current and fed to set- reset latch. A clock-pulse having switching period $T_{s}$ is provided at the set input causing the latch output $Q$ to be high and turning on the switch having gate pulse $G_{1}$ and reset the latch when ' $i_{l}$ ' sensed is greater than ' $i_{p}$ '. The battery initially replenishes charge at constant current according to the nominal battery charging current. Once it reaches to gassing voltage [9], the charging will be done through constant voltage and subsequently reaches to the fully charge voltage i.e. floating charge.
The salient feature of combining multiple house clusters with community bank as it makes the dc voltage regulated even after some battery packs are laid off due to undercharge or overcharge condition. The violation of SOC $(0.2 \leq S O C \leq 0.8)$ and $V_{\text {battery }}\left(48 \leq V_{\text {battery }} \leq 54\right)$ relay setting and the control of dc bus is taken by the other bidirectional controllers in standalone condition.

\section{PROTECTION SCHEME}

The dc fault analysis will focus on the natural response or the transient response of the second order RLC circuit shown in Fig 6.

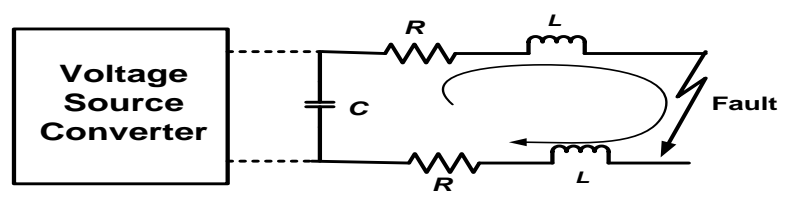

Fig. 6. DC fault analysis

The dc link capacitor discharges during fault having initial voltage $V_{c}(0)$. The role of low impedance connecting cables represented by R-L circuit is incorporated to study the severe short circuit condition having pre-fault inductor current represented by $i_{L}(0)$. The dotted portions show the homogenous equation analysis under natural response of the circuit as follows:

$$
L \frac{d i(t)}{d t}+R i(t)+\frac{1}{C} \int_{0^{-}}^{t} i(\tau) d \tau=0
$$

On taking laplace and arranging the terms, we get the fault response as follows

$$
i(s)=\frac{i_{L}(0) s+\left(V_{c}(0) / L\right)}{s^{2}+(\mathrm{R} / \mathrm{L}) \mathrm{s}+(1 / L C)}
$$

Taking characteristic equation in account and fault response is calculated for the under-damped and overdamped system as follows:

$$
\begin{aligned}
& i(t)=\frac{V_{c}(0) e^{-\alpha t}}{L w_{d}} \sin \left(w_{d} t\right) ; w_{o}^{2}>\alpha^{2} \\
& i(t)=\frac{V_{c}(0) e^{-\alpha t}}{L\left(s_{1}-s_{2}\right)}\left(e^{s_{1} t}-e^{s_{2} t}\right) ; w_{o}^{2}<\alpha^{2}
\end{aligned}
$$

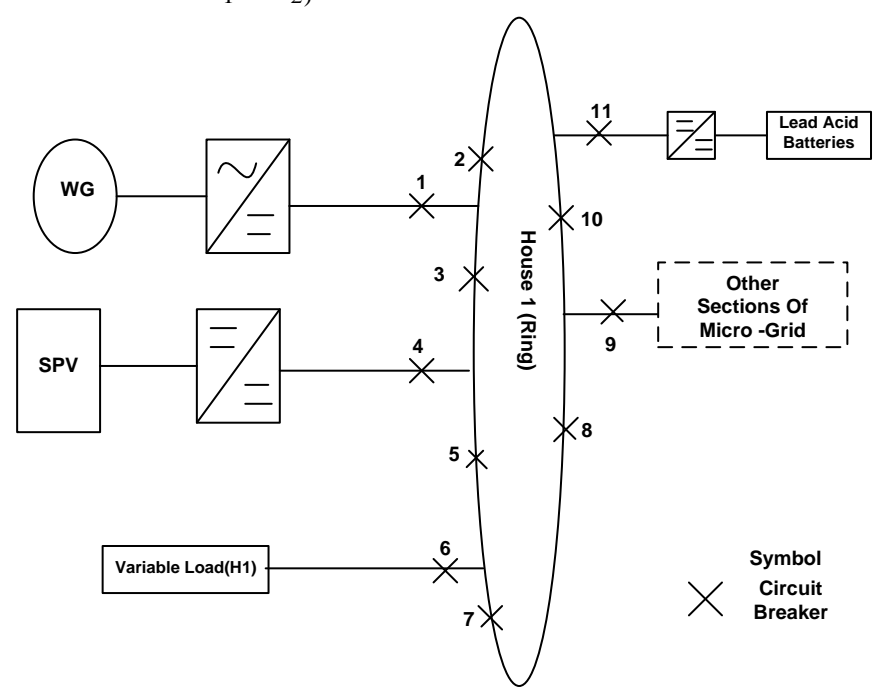

Fig. 7. Zone protection in ring configuration of house 1 . 
In the present configuration as shown in Fig 7, the unidirectional converter stages relate to wind generator and solar PV and bidirectional converter stages relate to the battery side. At the unidirectional converter stage, the direction of current flow can easily be investigated but the direction at the bidirectional converter stages is dependent on the charging and discharging of the battery. Thus the direction of current flow at the node connection is bidirectional. The ZRD rules for each converter stage is decided by the differential current measurement at the positive and negative pole and then comparison is made to the smaller threshold (say 1A) and according to the set points of various zones, tripping of circuit breaker is done.

$$
\text { ZRD Rule: } \quad i_{d c d i f f}=\left|i_{p}\right|-\left|i_{n}\right|
$$

where, $i_{p}$ is the positive pole of the converter and $i_{n}$ is the negative pole of the converter.

\section{Simulation RESUlTS}

To show the effectiveness of the proposed approach, the energy management is carried out under normal operating condition whereas the dc protection scheme is tested for the L-G fault. The various rating of the DGs and battery packs are given in Appendix A.

\section{A. Energy Management}

In this case, nominal wind speed is varied from $4 \mathrm{~m} / \mathrm{s}$ to $12 \mathrm{~m} / \mathrm{s}$ and solar irradiation is varied till 1000 watt $/ \mathrm{m}^{2}$ as per the availability of sunlight in day time. The wind power, solar PV power, dc link voltage profile are same for the two house clusters, and therefore, represented through a single waveform. However, variable load is made such that it suffices the real time profile of a residential load ranges from $2 \mathrm{~kW}$ to $10 \mathrm{~kW}$ for both the house clusters. The community load changes from $2.5 \mathrm{~kW}$ to $3 \mathrm{~kW}$. Variations of loads, wind power and PV output are shown in Figs. 8(a)-8(c).

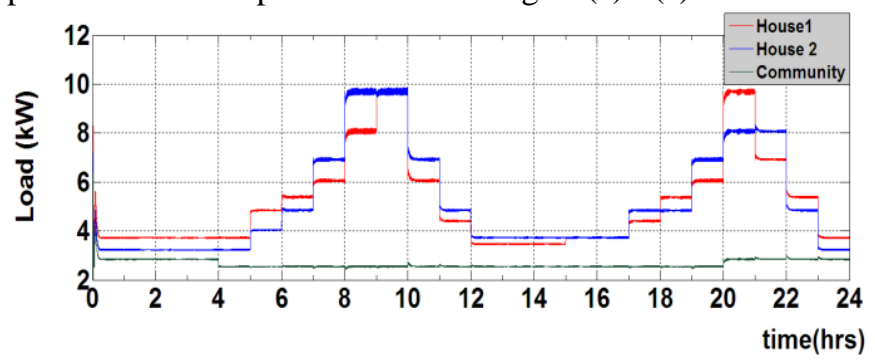

(a) House1, House2 and Community load profile.

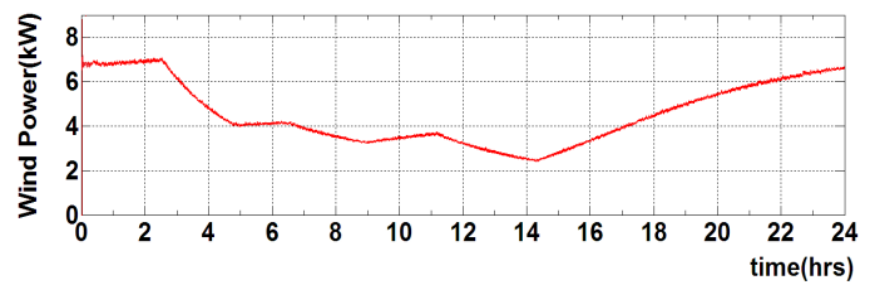

(b) Wind power profile for both the house cluster

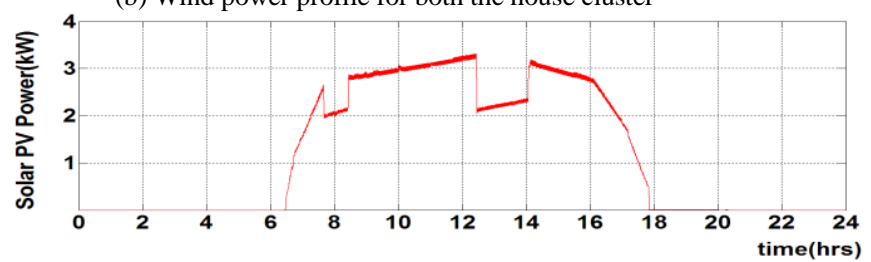

(c) Solar PV power profile for both the house cluster $\begin{array}{rr}22 & 24 \\ \text { time(hrs) }\end{array}$

Fig. 8. Variation of load, wind and PV output power.
From 0:00 to $6: 30 \mathrm{hrs}$ and $18: 00$ to $24: 00 \mathrm{hrs}$, the solar PV power is zero due to non-availability of sunlight and therefore, load demand is supplied only by wind generator and battery packs. During 7:00 to 18:00 hrs, the solar PV power ranges from 0 to $3.3 \mathrm{~kW}$ and wind power is reduced to the minimal value of $2 \mathrm{~kW}$ to $3 \mathrm{~kW}$. The power balance is shown in Figs. 9(a)-9(c).

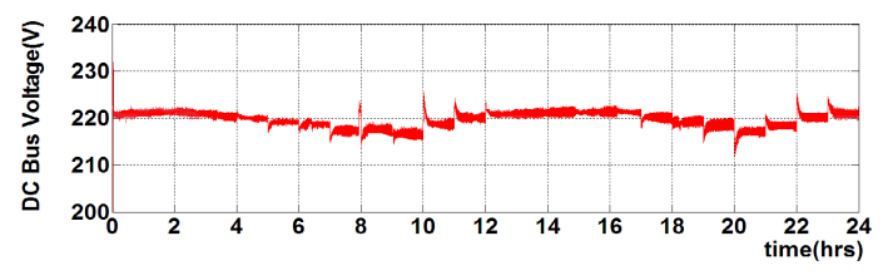

(a) DC bus voltage(V)

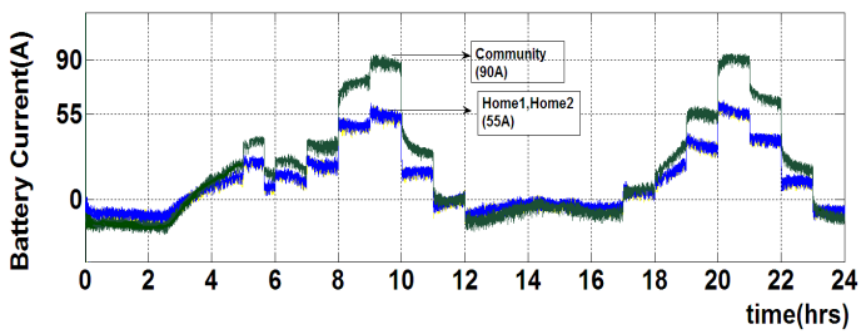

(b) Battery Power of $\mathrm{H} 1, \mathrm{H} 2$, Community $(\mathrm{kW})$

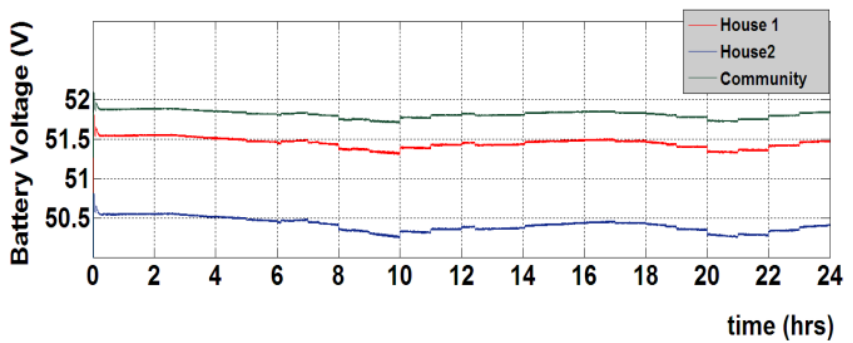

(c) Battery voltage of House1,House 2 and Community

Fig. 9. Simulation result at normal operating mode

The partial shading is caused by nearby objects or cloudy weather. For the duration of $7: 30$ to $8: 30 \mathrm{hrs}$ and $12: 30$ to 14:00 hrs, the current sharing concept is explained in Appendix B. The battery pack voltages is analyzed under such stress conditions and voltage observed as 51.4, 50.4 and $51.6 \mathrm{~V}$.

\section{B. DC Protection}

Case 1: Line to ground (LG) fault at the wind generator of House 1 linking unidirectional converter stage occurred at 1.2 $\mathrm{s}$ as shown in Fig. 10(a). The over current relay set-point is fixed at $58 \mathrm{~A}$ which is two times the rated current. The simulated waveform for the circuit breaker tripping $(\mathrm{CBw})$ and the response on dc bus voltage are shown in Fig. 10(b). The $\mathrm{CBw}$ is tripped at $1.208 \mathrm{~s}$ and the wind generator is isolated from the rest of the system. The dc bus voltage takes $0.02 \mathrm{~s}$ to recover $230 \mathrm{~V}$ that is the $5 \%$ off $220 \mathrm{~V}$.

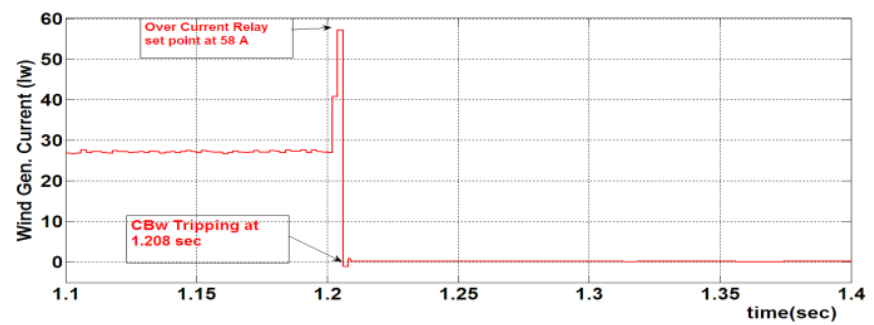

(a) L-G Fault Detection and Isolation of the Wind Generator 


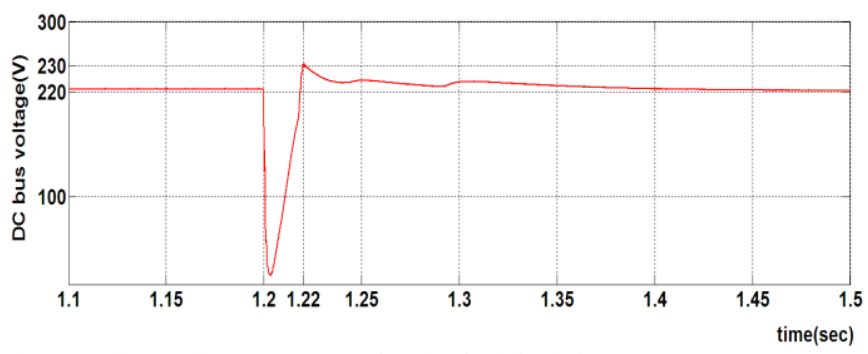

(b) DC bus Voltage response after the fault isolation

Fig. 10. Simulation results of over-current relay in L-G fault circuit breaker tripping.

Case 2: In this case, House-1 ring is considered and L-G fault is applied at $1.2 \mathrm{~s}$ before the battery converter stage. The battery side circuit breaker zone tripping involves circuit breakers $(2,10,11)$ and thus, each ring linking circuit breaker is driven under two zones. In case, if any failure of circuit breaker takes place at bi-directional converters stage zone, the fault can still be isolated by the proximity circuit breakers overlapped by the adjacent zones as shown in Figs. 11(a)-(c).

\section{CONCLUSION}

This paper addresses the stand-alone operation of small home clusters joined together to a dc bus. The community battery bank is used to avoid sudden charging/discharging of home cluster battery packs. For the effective controller design, the dc bus voltage is used as signaling reference to all the converters droop control loop and further, it gives reference to outer voltage loop control, which suffices the buck and boost modes for charging and discharging. To avoid instability issues of peak current mode control, the slope compensation technique is used. The dc protection covers the zone protection relaying by the set of rules pertaining to over current and current differential relaying under fault analysis is done.

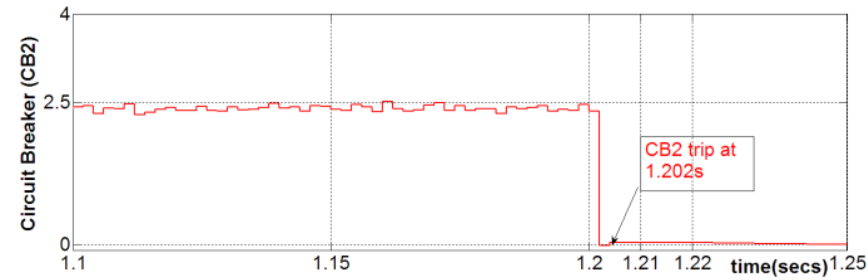

(a) Battery Zone Circuit Breaker (CB2) tripping response.

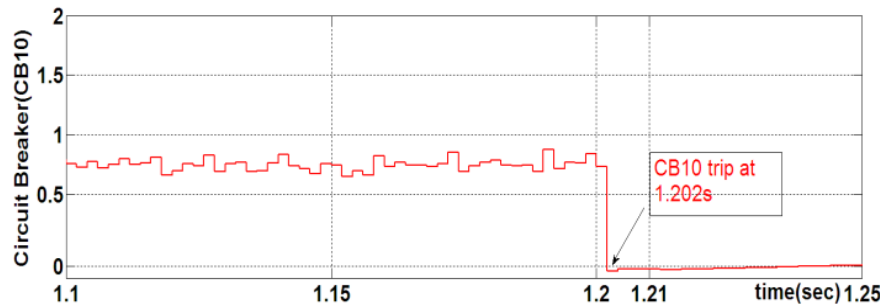

(a) Battery Zone Circuit Breaker (CB10) tripping response.

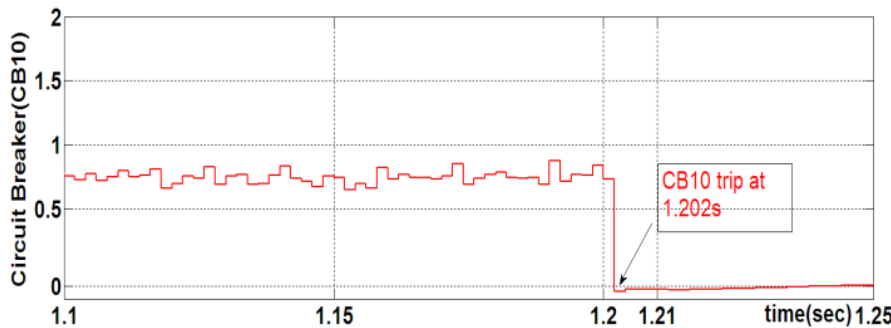

(c.) Battery Zone Circuit Breaker (CB11) tripping response.

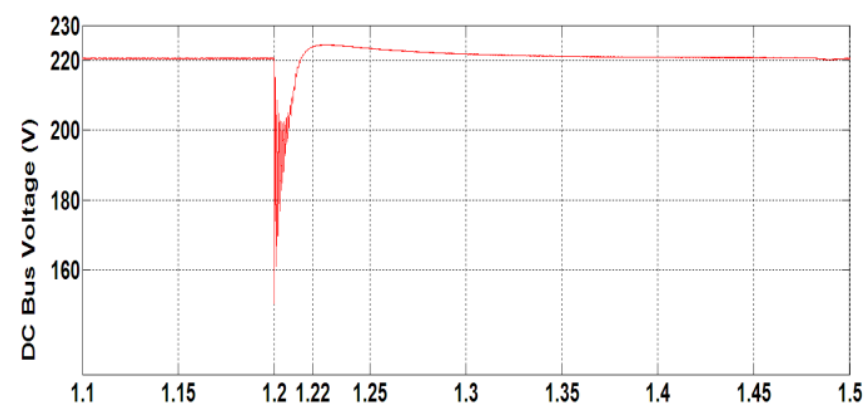

(d) DC bus voltage response after fault isolation

Fig. 11. Simulation results of Zone relaying device protection and fault isolation.

\section{APPENDIX A}

TABLE A.1: WIND, PV AND DC BUS RATINGS

\begin{tabular}{|l|l|}
\hline Rating of wind turbine generator & $7.5 \mathrm{~kW}$ \\
\hline Rating of Solar PV & $3.5 \mathrm{~kW}$ \\
\hline DC bus & $220 \mathrm{~V}$ \\
\hline
\end{tabular}

TABLE A.2: BATTERY RATINGS

\begin{tabular}{|l|l|}
\hline Battery(Home1,Home2) & $\begin{array}{l}\text { Nominal Voltage:48V } \\
\text { Fully charge voltage:54V } \\
\text { Ah rating:277.77 }\end{array}$ \\
\hline Community Battery & $\begin{array}{l}\text { Nominal Voltage:48V } \\
\text { Fully Charge Voltage:54V } \\
\text { Ah rating:347.22 }\end{array}$ \\
\hline
\end{tabular}

TABLE A.3: TRANSFER FUNCTION

\begin{tabular}{|l|c|}
\hline$G v(\mathrm{H} 1, \mathrm{H} 2, \mathrm{Com})$. & $\frac{0.00025 * \mathrm{~s}^{2}+0.01 s+0.1}{1.111 e-007 * s^{3}+0.001111 * s^{2}+s}$ \\
\hline
\end{tabular}

TABLE A.4: VIRTUAL RESISTANCE

\begin{tabular}{|l|l|l|l|}
\hline Rd(Home1) & $0.05990 \Omega$ \\
\hline Rd(Home2) & $0.05990 \Omega$ \\
\hline Rd(community) & $0.03544 \Omega$ \\
\hline \multicolumn{5}{|c|}{ TABLE A.5: DC CABLE } \\
\hline & Resistance & Inductance & Length \\
\hline H1,H2-Battery Side & $0.152 \mathrm{~m} \Omega / \mathrm{m}$ & $0.237 \mu \mathrm{H} / \mathrm{m}$ & $25 \mathrm{~m}$ \\
\hline $\begin{array}{l}\text { Community Battery } \\
\text { side }\end{array}$ & $0.152 \mathrm{~m} \Omega / \mathrm{m}$ & $0.237 \mu \mathrm{H} / \mathrm{m}$ & $60 \mathrm{~m}$ \\
\hline
\end{tabular}

\section{APPENDIX B}

Calculation of virtual resistance for $\pm 4.0 \mathrm{~V}$ deviation in $\mathrm{dc}$ bus, from (15) supposing the community battery current is 90A at peak demand duration in 9:00 to 10:00 hrs.. The virtual resistance can be calculated as follows.

For community battery pack:

$$
\begin{gathered}
216=220-90\left(R_{d, \text { com }}+0.009\right) \\
R_{d, \text { com }}=0.035444
\end{gathered}
$$

Total peak current is $200 \mathrm{~A}$ and it needs to be shared among the three battery packs, hence using the symmetry in (18), the virtual resistance for house clusters bidirectional converter is $R_{d, 1}=R_{d, 2}=0.05990$ for $55 \mathrm{~A}$ for each case.

\section{REFERENCES}

[1] F. G. Longatt, "Frequency Control and Inertial Response Schemes for the Future Power Networks," In Large Scale Renewable Power Generation, Springer Singapore, pp. 193-231, 2014.

[2] D. M. Bui, S. L. Chen, C. H. Wu, K. Y. Lien, C. H. Huang, and K. K. Jen, "Review on protection coordination strategies and development of an effective protection coordination system for DC micro grid," IEEE PES Asia-Pacific, Power and Energy Engineering Conference (APPEEC ), Honkong, pp. 1-10, 2014.

[3] J. J. Justo, F. Mwasilu, J. Lee, and J. W. Jung, "AC micro-grids versus DC- micro-grids with distributed energy sources: A review" Journal of Renewable and sustainable Energy Reviews, vol. 24, pp. 387-405, Aug. 2013. 
[4] S. Xu, C. Chen , Y. Jin, Y. Li, B. Li, and Y.Wang, "Protection for DC Distribution system with Distributed Generator" Journal of Apllied Mathematic, Article ID 241070, pp. 1-12, Jun. 2014.

[5] C. Abbey and G. Joos, "Short-term energy storage for wind energy applications," in Proc. Ind. Appl. Soc. Annu. Meet, Hong Kong, China, vol. 3, pp. 2035- 2042, Oct. 2005.

[6] M. E. Haque, M. Negnevitsky, and K. M. Muttaqi, "A novel control strategy for a variable-speed wind turbine with a permanent-magnet synchronous generator," IEEE Trans. Ind. Appl., vol. 46, no. 1, pp. 331-339, Nov. 2009.

[7] B. Subudhi and R. Pradhan, "A comparative study on maximum power point tracking techniques for photovoltaic power systems", IEEE Transactions on Sustainable Energy, vol. 4, no. 1, pp. 89-98, Jan. 2013.

[8] T. Esram and P. Chapman, "Comparison of Photovoltaic Array Maximum Power Point Tracking Techniques”, IEEE Transactions on Energy Conversion, vol. 22, no. 2, pp. 439-449, Jun. 2007.

[9] N. Achaibou, M. Haddadi, and A. Malek, "Lead Acid batteries simulation including experimental validation," Journal of Power Sources, vol. 185, no. 1, pp.1484-1491, Dec. 2008.

[10] K. Tan, and S. Islam, "Optimal control strategies in energy conversion of PMSG wind turbine system without mechanical sensors," IEEE Trans. Energy Conversion., vol. 19, no. 2, pp. 392-399, Jun. 2004.

[11] S. Morimoto, H. Nakayama, M. Sanada, and Y. Takeda "Sensorless Output Maximization Control for Variable-Speed Wind Generation System Using IPMSG", IEEE Trans. Ind. Appl., vol. 41, no. 1, pp. 6067, Jan./Feb. 2005.

[12] Y. Du, X. Zhou, S. Bai, S. Lukic and A. Huang, "Review of Nonisolated Bidirectional DC-DC Converters for Plug-in Hybrid Electric Vehicle Charge Station Application at Municipal Parking Decks" Applied Power Electronics Conference and Exposition (APEC), Palm Springs, CA, pp. 1145-1151, 2010. 